\section{A case of cutaneous large B-cell lymphoma of the legs appearing as chronic venous ulceration}

\author{
Marta Carlesimo, Diego Orsini, \\ Alessandra Narcisi, Claudia Abruzzese, \\ Giorgia Cortesi, Gabriella De Marco, \\ Alfredo Rossi \\ Dermatology Unit, S.Andrea Hospital, \\ Faculty of Medicine and Psychology \\ University of Rome La Sapienza, Italy
}

\begin{abstract}
We report here a case of a woman with a cutaneous large B-cell lymphoma of the legs. She had a plaque lesion, superficially ulcerated and necrotized with tumorous borders situated on the posterior side of the right leg and two red or bluish-red nodular lesions. A skin biopsy from both nodular and plaque lesion showed a diffuse infiltrate of atypical large B cells CD20+ and CD79a $\mathrm{a}^{+}$, spanning epidermis, dermis and subcutaneous tissue. A therapeutic approach containing anti-CD20 monoclonal antibody (rituximab) was suggested.
\end{abstract}

\section{Case Report}

A 83-year-old woman was referred to our Department, for a one year history of a large 15 $\mathrm{cm}$ diameter plaque lesion situated on the posterior side of the right leg, superficially ulcerated and necrotized, with tumorous borders; two red or bluish-red nodular lesions, of about 4-5 $\mathrm{cm}$ of diameters, were also located in the inferior leg (Figure 1A, B).

In the past she was treated for venous stasis ulceration with different topical and systemic therapies, without any improvement. The past medical history included systemic blood hypertension, chronic congestive heart failure and diabetes mellitus. The patient did not report any constitutional symptoms and haematochemical exams were all in the normal range. A skin biopsy from both nodular and plaque lesion showed a diffuse infiltrate of atypical large $\mathrm{B}$ cells $\mathrm{CD} 20^{+}$and $\mathrm{CD} 79 \mathrm{a}^{+}$, spanning epidermis, dermis and subcutaneous tissue; reactive T cells were also present (Figures 2A, B). A staging of the disease was done: no signs of extracutaneous lymphomas were found. So, the diagnosis of diffuse large B-cell lymphomas, leg type, was finally made. A therapeutic approach containing anti-CD20 monoclonal antibody (rituximab) was suggested to our patient, but she denied any kind of treatment.

\section{Discussion}

Cutaneous B cell lymphomas constitute about $20-25 \%$ of all primary cutaneous lymphomas. ${ }^{1,2}$ For long time there has been confusion and debate regarding the definition, terminology and treatment of different types of primary cutaneous B cell lymphomas. Finally in 2009, WHO-EORTC classification for cutaneous lymphomas summarized two types of primary cutaneous diffuse large B-cell lymphomas (DLBCL): DLBCL, leg type, and DLBCL, other. ${ }^{3}$ Clinically DLBCL leg type is characterized by rapidly growing tumour masses of lower leg with a percentage of about $10-15 \%$ of patients that could show skin lesions at sites other than the legs. Histologically, characteristic findings

include diffuse non-epidermotropic infiltrates predominantly made up of large noncleaved B-cells, with variable proportions of centroblast- and immunoblast-like cells. There are few if any admixed small cells and inflammatory cells. More often, the majority of neoplastic cells have the morphology of large non-cleaved follicle center cells. Tumor cells express CD19, CD20, CD22, and CD79a. These lymphomas generally strongly express the bcl-2 protein, but are not associated with the interchromosomal $\mathrm{t}(14 ; 18)$ translocation. Bcl-6 is expressed by most cases, whereas CD10 staining is generally absent. ${ }^{4}$

The prognosis is unfavourable for the frequent rate of metastasis located on lymph nodes and internal organs. ${ }^{4}$

Other types of lymphomas can affect the lower legs: rare cases of intravascular B cell lymphomas can occur; in addition, primary cutaneous immunocytomas preferentially involve arms or legs. ${ }^{5}$

Concerning therapies, there are two favourite therapeutic options: generally, in
Correspondence: Diego Orsini, Dermatology Unit, S.Andrea Hospital, Faculty of Medicine and Psychology University of Rome Sapienza, via di Grottarossa, 1035, 00189 Rome, Italy.

Tel: +39.06.33775822 - Fax: +39.06.33775378.

E-mail: diegoorsini@libero.it

Key words: primary cutaneous B cell lymphoma, B cell lymphoma of the leg, immunophenotype, therapy.

Received for publication: 5 August 2011.

Revision received: 23 January 2012.

Accepted for publication: 6 February 2012.

This work is licensed under a Creative Commons Attribution NonCommercial 3.0 License (CC BYNC 3.0).

(C) Copyright M. Carlesimo et al., 2012

Licensee PAGEPress srl, Italy

Hematology Reports 2012; 4:e6

doi:10.4081/hr.2012.e6

patients with a single skin tumour, radiotherapy may be considered as first choice treatment, with the improvement of the local control and disease-free survival; instead, in patients with multifocal skin lesions or relapses, cyclophosphamide, doxorubicin, vincristine, and prednisone (CHOP) chemotherapy is the standard systemic therapy for this disease with a cure rate of $40 \%$ to $50 \%{ }^{6}$ Recently it has been demonstrated that the anti-CD20 monoclonal antibody (Rituximab) is an effective treatment for PCLBCL LT, because of the monoclonal antibody ability to eliminate B neoplastic cells ${ }^{7}$ by direct induction of apoptosis, activation of complement- and antibody-dependent cellular cytotoxicity. ${ }^{8}$ Actually, rituximab in combination with CHOP has been accepted worldwide as the new standard therapeutic approach for the treatment of DLBCL. ${ }^{8}$

Our case-report shows a very unusual initial clinical presentation; in the literature only

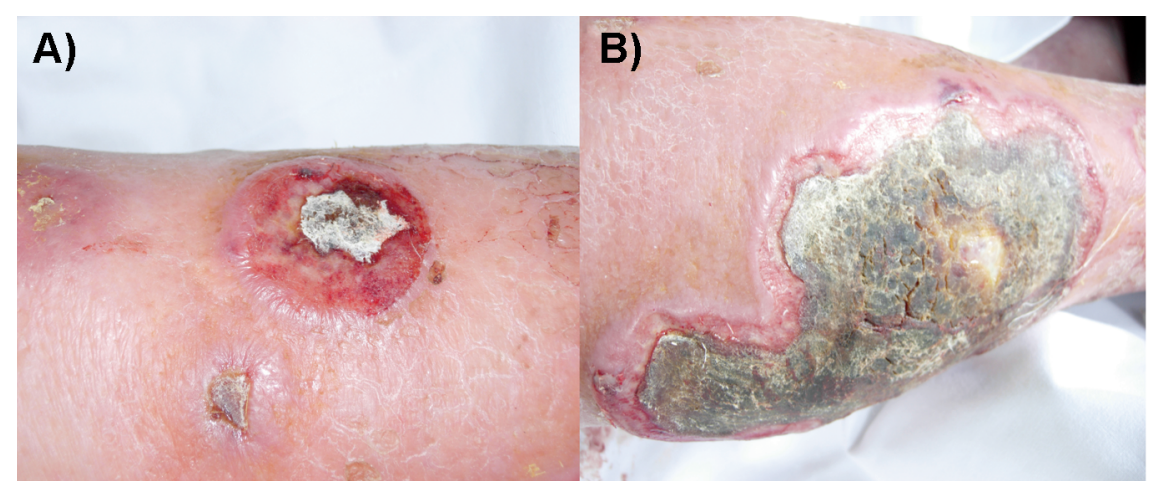

Figure 1. A) Eritematous nodular and partially ulcerated lesion, with a central escoriated zone and well defined edges; B) plaque lesion, partially necrotic in its central part, with eritematous and well defined edges. 
another case clinically similar has been described, ${ }^{7}$ therefore we want to underline the importance of considering a possible diagnosis of cutaneous lymphomas, in chronic ulcerations of the leg with an atypical clinical presentation a non-responsive behaviour to adequate therapies.

\section{References}

1. Willemze R, Kerl H, Sterry W, et al. EORTC classification for primary cutaneous lymphomas: a proposal from the cutaneous lymphoma study group of the European organization for research and treatment of cancer. Blood 1997;90:354-71.

2. Fink-Puches R, Zenahlik P, Bäck B, et al. Primary cutaneous lymphomas: applicability of current classification schemes (European Organization for Research and Treatment of Cancer, World Health Organization) based on clinicopathologic features observed in a large group of patients. Blood 2002;99:800-5.

3. Belousova IE, Vanecek T, Skreg SV, et al. Unusual clinicopathological presentation of primary cutaneous diffuse large B-cell lymphoma, leg type, with multiple nodules and widespread garland-like lesions. Am J Dermatopathol 2009;31:370-4.

132:1304-8.

6. Ng AK. Diffuse large B-cell lymphoma. Semin Radiat Oncol 2007;17:169-75. cutaneous B-cell lymphoma: further support for a follicle centre cell origin and differential diagnostic significance. Br $\mathrm{J}$ Dermatol 2003;149:1183-91.

5. Vermeer MH, Geelen FA, van Haselen CW, et al. Primary cutaneous large B-cell lymphomas of the legs. A distinct type of cutaneous B-cell lymphoma with an intermediate prognosis. Dutch Cutaneous Lymphoma Working group. Arch Dermatol 1996;
7. Süss A, Simon JC, Sticherling M. Primary cutaneous diffuse large B-cell lymphoma, leg type, with the clinical picture of chronic venous ulceration. Acta dermatovenereol 2007;87:169-70. ximab for the treatment of diffuse large Bcell lymphomas. Expert Rev Anticancer Ther 2006;6:1175-86.
8. Held G, Pöschel V, Pfreundschuh M. Ritu- 